\title{
EVALUATION OF PERFORMANCE OF HIGH CALCIUM FLY ASH AS A MINERAL FILLER IN MIX DESIGN OF MICROSURFACING OF ROAD PAVEMENT
}

\author{
Naitik Patel and Rajesh Gujar \\ Department of Civil Engineering, PDPU, Gandhinagar, India
}

\begin{abstract}
In the present research work, traditional mineral filler, high calcium Fly Ash, is used in the mix design of micro surfacing is evaluated with possibility of replacing it with other environmental friendly and cost effective selected fillers. The chemical analysis and material testing performed on high calcium Fly Ash filler indicate its suitability for incorporation in the mix design. The optimum mix design for microsurfacing Type II and Type III is determined through trial and error method. Also, the performance of a laboratory design mix is evaluated with field application. The field experimentation indicate that the mineral filler showed good performance for the test conducted on field after 24 hours and 6 months of application. The results evaluated in the field for skid resistance and surface texture indicate high calcium Fly Ash can be utilized for microsurfacing of road pavement.
\end{abstract}

\section{KEYWORDS}

Micro-surfacing, High Calcium Fly Ash, Skid Resistance, Surface Texture

\section{INTRODUCTION}

The performance of a pavement depends on its structural and functional condition. While structural condition depends on the load-carrying capacity of the pavement and subgrade, functional condition describes how "good" the road is in enabling a user to move from origin to destination under safe and comfortable conditions and at acceptable speed and cost. Preventive maintenance and surface rehabilitation techniques that can preserve and improve these functional conditions offer relatively low initial cost solutions and improved overall pavement performance. One promising new technology, microsurfacing, has been used in the United States as a surface rehabilitation technique for asphalt pavements since 1980. Micro-surfacing is a paving system composed of polymer-modified asphalt emulsion, 100 per cent crushed aggregate, mineral filler, water, and field control additives as needed. When properly designed and applied, it has shown good results in improving surface friction characteristics and filling wheel ruts and minor surface Irregularities on both low and high traffic volume roads. Microsurfacing has also been used as a surface seal and to address distresses such as flushing, oxidation, and ravelling. Performance results have been mixed but are generally encouraging for these applications as well. Microsurfacing used on Portland Cement Concrete (PCC) pavements and bridge decks has been relatively limited but is usually satisfactory.

Microsurfacing is a road maintenance tool that involves laying a mixture of dense-graded aggregates, asphalt emulsion (about 5.5 to $10.5 \%$ by weight), water (up to $15 \%$ as required to 
produce proper mix consistency), polymer additive (about $3 \%$ by weight) and mineral fillers (about 3\% of weight of total dry mix) to correct or prevent certain deficiencies in pavement conditions. In the same category of pavement treatments as seal coating and thin Hot Mix Asphalt (HMA) overlays, microsurfacing treatments cover the entire width of the roadway to which they are applied.

The treatment may be as thin as $9.5 \mathrm{~mm}$ or it can fill wheel ruts up to $50.8 \mathrm{~mm}$ deep using multiple passes. Because of the similar ingredients used in microsurfacing as in slurry seals, microsurfacing is sometimes referred to as a "polymer-modified slurry seal." The primary difference between the two treatments slurry seals and microsurfacing is that slurry seal utilizes thermal curing process while microsurfacing utilizes a chemically controlled curing process. One of the main benefits achieved from microsurfacing over alternative pavement treatments results from the polymer-modified asphalt emulsion that chemically speeds evaporation of moisture. Rapid breaking of the mixture enables it to set in less than one hour in most instances, requires no rolling, and allows traffic to return to the roadway quickly.

Despite the chemically controlled breaking process, microsurfacing should not be applied if either the pavement or air temperature is below $50^{\circ} \mathrm{F}\left(10^{\circ} \mathrm{C}\right)$ nor if there is a possibility of the treatment freezing within 24 hours of placement. Additionally, since the use of a polymer modified binder results in greater mix stability, microsurfacing can be placed in multi-stone thicknesses, unlike slurry seals. Due to the increased viscosity of the mix, more powerful mixers needed for microsurfacing than slurry seals and in order to provide a uniform flow of the mixture into the spreader box, a twin-shafted paddle or spiral auger is needed (ISSA).

Generally microsurfacing is classified as a preventative maintenance treatment opposed to corrective maintenance treatment because of its significant ability to seal and restore pavement surfaces and its inability to improve structural defects. Due to this classification by agencies involved in road repair and maintenance, it is most often used as a surface treatment to correct rutting, improve surface friction, and extend pavement life by sealing any cracks in the pavement surface.

Ordinary Portland Cement (OPC) is used as conventional mineral filler in microsurfacing mix. Cement is one of the most environmentally hazardous materials in the world, adding more carbon dioxide to the atmosphere than the entire weight of the global airline industry (The Guardian, 2006). To reduce the environmental impact by cement and to offer relatively low initial cost solutions for preventive maintenance various microsurfacing agencies are in the need of alternative mineral filler which can replace the cement and give effective results.

Since micro-surfacing is a mixture of various materials, any change in a single component changes the performance of the system (Hassan, R. 1994). Accordingly, a number of laboratory specimens are required to be prepared and subjected to empirical testing. This involves the preparation of trial mixes with variations in the content of asphalt emulsion, water, mineral filler, and additives as desired to determine the effects of changes on mixing, breaking, and setting characteristics in order to ensure good control of the system in the field.

\section{LITERATURE REVIEW}

Microsurfacing was developed in Germany in the late 1960s and early 1970s. It was introduced as a way to apply conventional slurry in enough thick layers to fill deep wheel ruts, also in enough narrow courses so that the expensive road striping lines on the highways would not be destroyed. It was introduced to the United States (US) in 1980 after Dr. Frederick Raschig presented his new slurry system at the International Slurry Surfacing Association (ISSA) convention (Broughton et 
al., 2012). Microsurfacing is now used throughout Europe, US, and Australia. The main benefit achieved from microsurfacing over alternative pavement treatments is that the polymer-modified asphalt emulsion that chemically speeds evaporation of moisture which enables it to set in less than one hour, while in most instances requires no rolling, and allows traffic to return to the roadway quickly.

Hajj et al. (2010) conducted a study to evaluate the long-term performance of asphalt pavement preservation activities. The overall observation suggested that lower the pre-treatment PSI (Present Serviceability Index), the higher the reported pavement distresses and vice versa.

Zhao et al. (2010) carried out a comprehensive analysis and elaboration about micro-surfacing from the aspect of raw material choice, mixture ratio design, construction and quality control and it was proved that microsurfacing may prevent the road surface effectively with plant repair wheel rut.

Gransberg (2009) explored the economics of replacing chip sealing and thin hot mix asphalt overlays for highways with surface retexturing with the same shot blasting technology that was used on airport pavements and vice versa.

Labi et al. (2006) carried out investigation to understand the long-term benefits of microsurfacing application. The results showed that for each and performance indicator, the treatment effectiveness was influenced by climate, traffic loading, and highway class. The results also showed that the effectiveness of microsurfacing is most perceptible when rutting is used as the performance indicator.

Sharma et al. (2010) conducted a study on characterization of fly ash bituminous concrete mixes, fly ashes collected from 14 thermal power stations located in different parts of India and were characterized, It indicated that all the four groups of fly ashes are suitable for use in BC mixes with fly ashes in group 4 having the best performance. The optimum filler content is $7 \%$ and properties of fly ash $\mathrm{BC}$ mixes are better than those of conventional mix.

Lyon and Persaud (2008) concluded that skid-resistance improvement projects targeted at locations with low skid resistance and a correspondingly high frequency of wet weather accidents can yield substantial safety benefits for both road segments and intersections.

In the present research efforts has been made, to identify alternative fillers in microsurfacing mix replacing OPC, evaluate effect of filler proportion through laboratory tests, assess performance of microsurfacing mix through field tests.

\title{
3. RESEARCH METHODOLOGY
}

In this chapter, materials used for the present study and their role in microsurfacing are discussed. The basic materials used in microsurfacing mix are as follows:

\author{
i. Aggregate (Type II \& Type III) \\ ii. Emulsified Asphalt \\ iii. Control Additives \\ iv. Water
}


Civil Engineering and Urban Planning: An International Journal (CiVEJ ) Vol.4, No.2, June 2017

\section{v. Copper Slag as Mineral Fillers}

\subsection{Aggregate}

The key physical characteristics of aggregate necessary for selection of microsurfacing mix are govern by geology, shape, texture, age and reactivity, cleanliness, soundness, and abrasion resistance. Geology determines the aggregate's compatibility with the emulsion in addition to its adhesive and cohesive properties.

The quality of the aggregate is critical since aggregate constitutes approximately $94 \%$ by weight of the finished microsurfacing treatment. The aggregate should be a crushed stone such as granite, slag, limestone, chert, or another high-quality aggregate, or combination thereof. The aggregate must be $100 \%$ crushed and be densely graded to meet the requirements of one of the two gradations; Type II or Type III

Type II This aggregate gradation is used to fill surface voids, address surface distresses, seal, and provide a durable wearing surface.

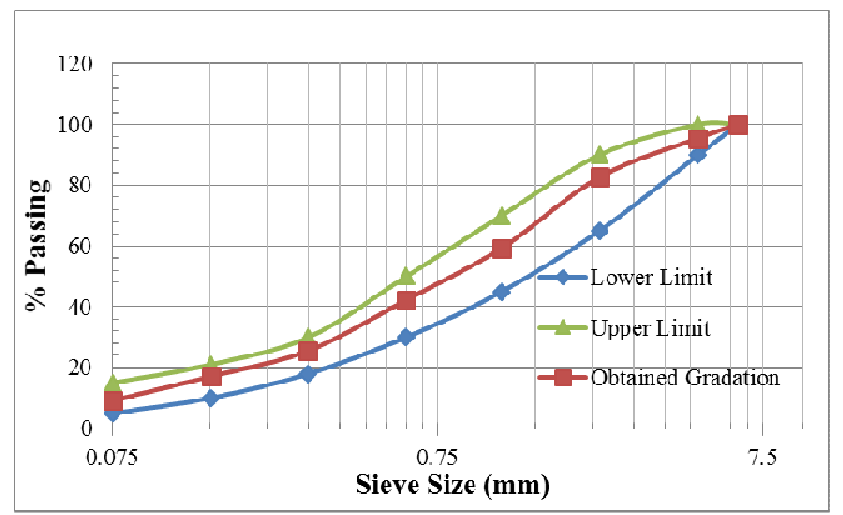

Figure 1 Grain Size Distribution Curve of Type II Aggregates

Type III This aggregate gradation provides maximum skid resistance and an improved wearing surface. This type of micro surfacing surface is appropriate for heavily travelled pavements, rut filling, or for placement on highly textured surfaces requiring large size aggregate to fill voids.

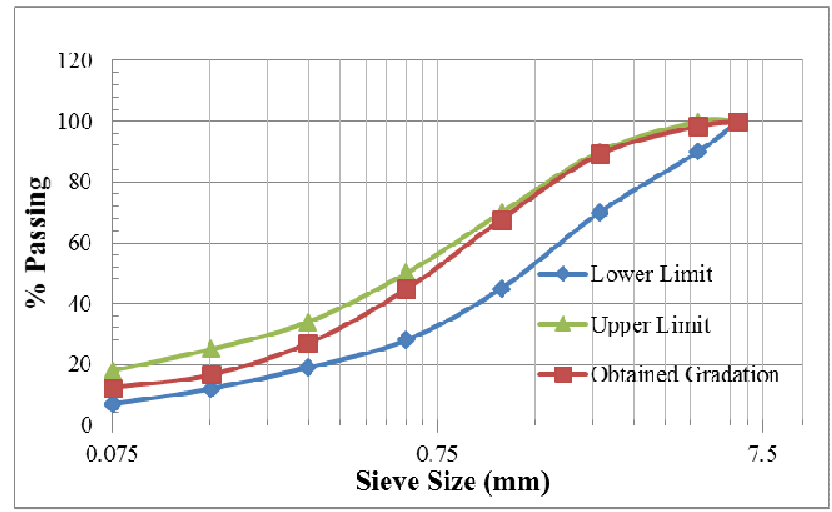

Figure 2 Grain Size Distribution Curve of Type III Aggregates 


\subsection{Bitumen Emulsion}

In the present study a cationic bitumen emulsion modified with latex was used. The source of polymer modified emulsion is Tikitar Industries Limited (Baroda, Gujarat). In the laboratory analysis of bitumen emulation characteristic properties like Residue on 600 micron IS Sieve (\% by mass), Viscosity by Say Bolt Furol Viscometer, at 25oC, in second, Coagulation of emulsion at low temperature and Storage Stability after 24 hours is determined using IS: 8887 at $250 \mathrm{C}$ Temperature. Emulsion's characteristics, which meet the requirements as per IRC:SP:81-2008 specification are shown in Table 3.1 .

(Table 1. Characteristic Properties of Polymer Modified Bitumen Emulsion)

\begin{tabular}{|l|c|}
\hline \multicolumn{1}{|c|}{ Test Name } & Test Value \\
\hline Residue on 600 micron IS Sieve (\% by mass) & 0.039 \\
\hline Viscosity by Say Bolt Furol Viscometer at $25^{\circ} \mathrm{C}$, in second & 22 \\
\hline Coagulation of emulsion at low temperature & Nil \\
\hline Storage Ability after $24 \mathrm{~h}, \%$ & 1.5 \\
\hline Particle charge, + ve/-ve & Positive [+ve] \\
\hline Residue by evaporation, $\%$ & 63.5 \\
\hline Penetration at $25^{\circ} \mathrm{C} / 100 \mathrm{~g} / 5 \mathrm{~s}$ & 47 \\
\hline Ductility at $27^{\circ} \mathrm{C}, \mathrm{cm}$ & 55 \\
\hline Softening Point, in ${ }^{0} \mathrm{C}$ & 58.5 \\
\hline Elastic Recovery & 51.5 \\
\hline Solubility in trichloroethylene, $\%$ & 98.5 \\
\hline
\end{tabular}

\subsection{Field Control Additive}

Although an additive is used to either accelerate or retard the break time of microsurfacing mixtures, the additive is commonly used to retard the break time. Generally, the emulsifier used in emulsion manufacturing, is used as an additive because of its compatibility with other mixture components. In the present study, bitumen emulsion from Tikitar (bitumen manufacturer) has been used as a control additive, Tikitar make additive is used which contains TELCODINAC-S$10 \%$, TELCODINAC - MAC - 2\%, HCL - $12 \%$, Balance Water.

\subsection{Water}

It is the mixing medium for the micro-surfacing mixtures. It is the main factor determining mixture consistency. It is introduced in three ways: as moisture already in the aggregate, as mixing water, and as one of the two major constituents of the emulsion. All potable water can generally be used for micro-surfacing. Normally, water quality is not as much an issue as is quantity.

\subsection{Ordinary Portland Cement}

Conventionally Portland cement and hydrated lime have been used as mineral filler for microsurfacing. In the present study Ordinary Portland cement of Ultratech make 53 Grade was used for micro-surfacing. Table 3.6 shows the chemical composition of Ordinary Portland Cement obtained in laboratory tests performed as per IS 4032.3.2. 


\subsection{High Calcium Fly Ash}

Fly ash is one of the residues generated in combustion, and comprises the fine particles that rise with the flue gases. Ash which does not rise is termed as "bottom ash". In an industrial context, fly ash usually refers to ash produced during combustion of coal. Fly ash is generally captured by electrostatic precipitators or other particle filtration equipment before the flue gases reach the chimneys of coal-fired power plants and together with bottom ash removed from the bottom of the furnace.

Depending upon the source of the coal being burned, the components of fly ash vary considerably, but all fly ash includes substantial amounts of silicon dioxide ( $\mathrm{SiO} 2)$ (both amorphous and crystalline) and calcium oxide $(\mathrm{CaO})$, both being endemic ingredients in many coal-bearing rock strata. Fly ash is generally highly heterogeneous, consisting of a mixture of glassy particles with various identifiable crystalline phases such as quartz and various iron oxides. Chemical composition of Fly Ash obtained in laboratory tests performed as per IS 1727 is shown in Table 2.

(Table 2. Chemical Composition of High Calcium Fly Ash)

\begin{tabular}{|l|c|c|r|}
\hline \multicolumn{1}{|c|}{ Parameter } & $\begin{array}{c}\text { Test Method } \\
\text { Standard }\end{array}$ & $\begin{array}{c}\text { Results } \\
\text { obtained in } \\
\%\end{array}$ & $\begin{array}{c}\text { Specifications } \\
\text { As per IRC:SP: 89- } \\
2010\end{array}$ \\
\hline $\mathrm{Fe}_{2} \mathrm{O}_{3}+\mathrm{Al}_{2} \mathrm{O}_{3}+\mathrm{SiO}_{2}$ & IS-1727 & 68.78 & $70 \% \mathrm{Min}$ \\
\hline $\mathrm{SiO}_{2}$ & IS-1727 & 60.96 & $25 \% \mathrm{Max}$ \\
\hline $\mathrm{MgO}$ & IS-1727 & 9.67 & $2.75 \% \mathrm{Max}$ \\
\hline $\mathrm{SO}_{3}$ & IS-1727 & 0.670 & $0.05 \mathrm{Max}$ \\
\hline $\begin{array}{l}\mathrm{Available} \mathrm{Alkalis} \mathrm{as} \\
\mathrm{Na}_{2} \mathrm{O} / \mathrm{K}_{2} \mathrm{O} \text { in } \% \text { by Mass }\end{array}$ & IS-4031 & 0.003 & $5 \mathrm{Max}$ \\
\hline $\mathrm{Cl}_{2}$ & IS-1727 & 0.013 & -- \\
\hline $\mathrm{Loss}$ of Ignition & IS-1727 & 2.28 & -- \\
\hline $\mathrm{CaO}$ & IS-1727 & 18.42 & 7.82 \\
\hline $\begin{array}{l}\mathrm{Combined} \mathrm{Fe}_{2} \mathrm{O}_{3} \& \mathrm{Al}_{2} \mathrm{O}_{3} \\
\% \text { by mass }\end{array}$ & IS-1727 & & \\
\hline
\end{tabular}

\section{MiCROSURFACING MiX EVALUATION AND DATA ANALYSIS}

The ultimate purpose of a mix design procedure is to recommend the right "combination" of emulsion, aggregate, water, and alternative filler to produce a mix that will perform under specific conditions. A different mix design may be desirable when a quick set micro-surfacing mix is placed under high temperature-low humidity conditions versus a slow setting mix placed in lowtemperature high-humidity conditions. Estimated future traffic and environmental conditions are also influences the choice of a certain mix design. The mix design was performed according to IRC: SP: 81-2008 specifications.

\subsection{Laboratory Evaluation}

As in any surface mix, good quality materials are important for the proper performance of microsurfacing mixtures. However, good quality materials alone may not ensure a satisfactory micro-surfacing mixture, since some good quality materials may be incompatible when mixed together. This is the reason that mixture tests are so important in evaluating microsurfacing. 
Mixture testing is performed to determine (1) the mixing and application characteristics of the constituents and (2) optimum asphalt cement content.

To examine suitability of every trial mix following test were performed:

\section{i. Manual Mixing Test}

Samples $200 \mathrm{~g}$ aggregate were hand-mixed with filler, water (optionally containing control additive) and emulsion. After 30 seconds part of the mix was poured out and the remainder was stirred until the emulsion breaks (,mix time $\left.{ }^{e e}\right)$. The poured-out sample was checked for clear water exuding by patting with filter paper. When the water is clear this gives the approximate ,set time ${ }^{e c}$. Mix times in the range of 30-180 seconds may be acceptable depending "on the type of paver" used.

\section{ii. Cohesion Test}

The cohesion tester is a power steering simulator that measures the torque required to tear apart a 6 or $8 \mathrm{~mm}$ thick x $60 \mathrm{~mm}$ in diameter specimen under the action of a $32 \mathrm{~mm}$ diameter rubber foot loaded to $200 \mathrm{KPa}$. Torque measurements are made at suitable time intervals such as 20, 30, 60, $90,150,210$, and 270 minutes after casting. In this study cohesion test was performed according to IRC: SP: 81-2008.

\section{iii. Wet Track Abrasion Test (WTAT)}

This test simulates wet abrasive conditions such as vehicle cornering and breaking. A cured sample $6 \mathrm{~mm}$ thick x $280 \mathrm{~mm}$ in diameter that has been soaked for periods of either 1hour or 6 days is immersed in a $250 \mathrm{C}$ water pan and is wet abraded by a rotating weighted $(2.3 \mathrm{~kg})$ rubber hose for 5 minutes. The abraded specimen is dried to $600 \mathrm{C}$ and weighed. Maximum allowed weight losses for one hour and 6 day soaks are $540 \mathrm{~g} / \mathrm{m} 2$ and $800 \mathrm{~g} / \mathrm{m} 2$, respectively. In this study wet track abrasion test was performed according to IRC: SP: 81-2008.

\subsection{Field Evaluation}

\section{i. Skid Resistance}

The skid resistance was conducted after application of 24 hours following ASTM E303-93 standard test method for measuring surface frictional properties using the British Pendulum Tester. As per BS 812: 1967, the minimum value of skid number required for pavements of the study road should be 45 .

\section{ii. Surface Texture}

The ability of bituminous surface to provide the required skid resistance is governed by its micro texture and macro texture. Macro texture depth is measured by sand patch method (ASTM: E 965- 83). Macro texture plays a dominant role in availability of friction on wet surfaces at high speed. To measure texture depth a well-known volume of sand (passing 300 micron sieve \& retained on 150 micron sieve) is spread over test surface. Mean texture depth is then determined by diving volume by area covered. This method is essentially used for determining pavement skid resistance capability and the suitability of paving materials or finishing techniques. 
Surface texture is classified based on macro texture depth as (i) coarse texture: $>0.50 \mathrm{~mm}$ (ii) medium texture: $0.50-0.25 \mathrm{~mm}$ (iii) fine texture: $<0.25 \mathrm{~mm}$. As per IRC: $15-2002$, the values should be between $0.65 \mathrm{~mm}$ to $1.25 \mathrm{~mm}$.

iii. Roughness

The surface unevenness of highway pavements refers to the regularity of surface finish both in longitudinal and transverse directions. The existing standards and tolerances of surface unevenness are prescribed in IRC: SP: 16-2004.

\section{RESULTS}

\subsection{Laboratory Investigation}

In microsurfacing mix trials, components other than mineral filler and additive were kept constant for laboratory evaluation of microsurfacing mix. Laboratory evaluation was done for both Type II as well as Type III. 56 Number of mix trials with increasing percentage of fillers and additives for microsurfacing Type II and Type III were prepared and tested.

The laboratory tests as per IRC: SP: 81-2008 specifications were performed varying the percentage of Cement \& Copper Slag, keeping percentage of other ingredients constant and results were compared with the prescribed standards. So far as variability is concerned there is no standard for variability range suggested for these tests. As best Engineered Mix has been selected based on its performance both during laboratory tests as well as field tests, subject to the alternate fillers qualifying the thresholds limits stated in IRC SP: 81 2008, the variability of the test results has not been considered.

(Table 3. Variability Seen with Increase of Additives \& Fillers for Type II and Type III Microsurfacing Mix)

\begin{tabular}{|c|c|c|c|c|}
\hline \multirow{2}{*}{} & \multicolumn{2}{|c|}{ Type II Microsurfacing Mix } & \multicolumn{2}{c|}{ Type III Microsurfacing Mix } \\
\cline { 2 - 5 } & Cement & Fly Ash & Cement & Fly Ash \\
\hline Mixing Time (Sec) & $-8.40 \%$ & $-8.99 \%$ & $-8.99 \%$ & $-9.93 \%$ \\
\hline Cohesion (30min) & $21.28 \%$ & $18.28 \%$ & $25.76 \%$ & $33.51 \%$ \\
\hline Cohesion (60min) & $10.32 \%$ & $11.10 \%$ & $11.09 \%$ & $14.43 \%$ \\
\hline Set Time (Sec) & $-8.40 \%$ & $-8.99 \%$ & $-8.99 \%$ & $-9.93 \%$ \\
\hline Weight Loss & $-5.23 \%$ & $-6.17 \%$ & $-4.77 \%$ & $-5.74 \%$ \\
\hline
\end{tabular}

\subsection{Field Investigation}

Microsurfacing which is applied to fill wheel ruts and provides a texturing course with improved surface friction characteristics is measured by measuring skid resistance, Roughness and Surface texture. The tests are performed after 24 hours and 6 months of laying microsurfacing. 
Civil Engineering and Urban Planning: An International Journal (CiVEJ ) Vol.4, No.2, June 2017

(Table 4. Field Test Results for Microsurfacing)

\begin{tabular}{|c|c|c|c|}
\hline & $\begin{array}{c}\text { Without } \\
\text { Microsurfacing }\end{array}$ & With Cement & $\begin{array}{c}\text { With High calcium } \\
\text { Fly Ash }\end{array}$ \\
\hline Skid Resistance @24 Hrs. & 40 & 80 & 65 \\
\hline Skid Resistance @6 Months & 40 & 80 & 50 \\
\hline Surface Texture @24 Hrs. & - & 0.97 & 0.81 \\
\hline Surface Texture @6 Months. & - & 0.97 & 0.78 \\
\hline Roughness @24 Hrs. & 2498 & 1506 & 1872 \\
\hline Roughness @6 Months & 2498 & 1596 & 2065 \\
\hline
\end{tabular}

\section{CONCLUSIONS}

Microsurfacing mix generally uses limestone filler or most often cement. It has a double role to play in the mixture to bring the percentage of filler to the required amount and to accelerate the breaking time of the modified asphalt emulsion (the alkaline-based filler reacts with the acidbased emulsion). Owing to the concern of environmental pollution caused due to production of cement and judicious utilization of industrial waste research works have been focused on replacement of cement by industrial waste in road pavements. In the present study, research was done to select the most suitable alternative fillers in microsurfacing mix.

The traditional mineral fillers used in the mix design of micro surfacing were evaluated with possibility of replacing it with other environmental friendly and cost effective selected fillers for which exhaustive laboratory and field experimentation were carried out. Fly Ash was assessed through chemical analysis as well as rigorous laboratory and field tests, which indicated positive results for its incorporation into mix design for microsurfacing.

\section{REFERENCES}

[1] Ali, N., Chan, J. S., Simms, S., Bushman, R., \& Bergan, A. T. (1996). Mechanistic evaluation of fly ash asphalt concrete mixtures. Journal of materials in Civil Engineering, 8(1), 19-25.

[2] Broughton, B., Lee, S. J., \& Kim, Y. J. (2012). 30 Years of Microsurfacing: A Review. ISRN Civil Engineering.

[3] Hajj, E. Y., Loria, L., \& Sebaaly, P. E. (2010). Performance Evaluation of Asphalt Pavement Preservation Activities. Transportation Research Record: Journal of the Transportation Research Board, 2150(1), 36-46.

[4] Zhao, F., Wang, K., \& Zhang, S. (2010). Application of microsurfacing in pavement preventive maintenance for shen-shan freeway. International Conference IEEE, 1-4.

[5] Gransberg, D. D. (2009). Life-cycle cost analysis of surface retexturing with shotblasting as an asphalt pavement preservation tool. Transportation Research Record: Journal of the Transportation Research Board, 2108(1), 46-52.

[6] Labi, S., Hwee, K. S., Lamptey, G., \& Nunoo, C. (2006). Long-term Benefits of Microsurfacing Applications in Indiana-Methodology and Case Study. In Proceedings: 85 th Annual Meeting of the Transportation Research Board.

[7] Sharma, V., Chandra, S., \& Choudhary, R. (2010). Characterization of fly ash bituminous concrete mixes. Journal of Materials in Civil Engineering, 22(12), 1209-1216. 
Civil Engineering and Urban Planning: An International Journal (CiVEJ ) Vol.4, No.2, June 2017

[8] Lyon, C., \& Persaud, B. (2008). Safety effects of targeted program to improve skid resistance. Transportation Research Record: Journal of the Transportation Research Board, 2068(1), 135-140.

\section{AUTHOR}

Naitik Patel is a student from Gandhinagar, India. He is perusing B.Tech. in Civil Engineering from Pandit Deendayal Petroleum University, Gandhinagar. $\mathrm{He}$ is a founder of M/s Dharti SoilTech and passionate about automation and innovation in Civil Industry. His current research interests includes building health monitoring, ground improvement techniques.

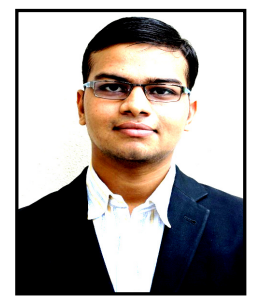

